\title{
ORIENTAR SEGUNDO A METODOLOGIA ORIENTADA PARA O CONTEXTO E O INVESTIGADOR: PARTE I QUESTÕES TEÓRICAS E METODOLÓGICAS
}

\author{
Serafim Camalhão ${ }^{1}$ e Horácio Saraiva ${ }^{2}$ \\ ${ }^{1}$ ISCTE IUL, Portugal. serafimleopoldo@hotmail.com; \\ ${ }^{2}$ Escola Superior de Educação João de Deus, Portugal. horaciosaraiva@gmail.com
}

\begin{abstract}
Resumo. Orientar teses e dissertações é um dos desafios que se colocam quer a orientadores quer a orientandos. Na metodologia orientada para o contexto e o investigador preocupamo-nos em colocar ao conhecimento e a investigação um triplo desafio: estar acessível a todos, estar mais próxima da realidade e que seja exequível tendo em conta o investigador concreto e não em abstracto. Nos livros de metodologia as questões da orientação colocam-se principalmente a nível prático. A pouca integração teórica sobre as práticas a nível metodológico, dificulta a compreensão do que se está falar. É um tema complexo, o qual originou dois artigos, independentes, mas que se complementam. A primeira parte aborda questões teóricas e de caracter mais filosófico, o segundo mais orientado para a prática. O centro da nossa atenção está a nível micro, numa uma relação privilegiada entre orientador e orientando com o fim de levar a bom termo um trabalho académico. Defendemos que mesmo que o resultado de uma investigação seja generalizável, o processo que a construiu é único e irrepetível.
\end{abstract}

Palavras-chave: Orientar; Investigar; Metodologia; Teoria; Pedagogia.

\section{DIRECTING ACCORDING TO METHODOLOGY ORIENTED FOR THE CONTEXT AND RESEARCHER: PART I: THEORETICAL AND METHODOLOGICAL QUESTIONS}

\begin{abstract}
Guiding master dissertations and doctoral theses is one of the challenges faced for both the professors' supervisors and the supervised students. In the methodology oriented for the context and researcher, we are concerned in posing to the knowledge and researcher one triple challenge: to be accessible to all, to be closer to the reality and to be workable, taking in account the concrete researcher and not in abstract. In the books of methodology the questions of orientations, are posed in a practical level. The little theoretical integration and framework, makes more difficult the understanding of what is spoken. It is a complex theme, which produced two articles, they are independent but also complement each other. The first part discusses the theoretical questions and character more philosophical, the second is more oriented to practical aspects. The centre of our orientation is at a micro level, in privileged relation between supervised and oriented, with the aim of taking the academic work at a good end.
\end{abstract}

Keywords: Supervising; Researching; Methodology; Theory; Pedagogy.

\section{INTRODUÇÃO}

As questões ligadas ao tema da orientação de Dissertações de Mestrado e Teses de Doutoramento são dos temas mais discutidos no meio académico. O tema não é novo nas Ciências Sociais e Humanas, embora possam existir referências mais antigas, o primeiro contacto que os autores deste artigo tiveram com este problema está em Eco (1991) na obra "Como se faz uma tese em ciências humanas" em que originalmente publicado em 1977. Nesta obra observam-se as diferenças entre alunos universitários tendo em conta o seu contexto social, cultural e económico, assim como, com os problemas colocados à orientação na óptica dos alunos. Também é um tema discutido nos congressos, nomeadamente do CIAIQ 
que em 2013, Amado (2013) num painel de discussão colocava os problemas da investigação qualitativa e necessidades de formação face ao Processo de Bolonha. Numa referência mais actual está o workshop realizado no CIAIQ 2019 onde Taquette, Souza e Maher (2019) numa proposta de ensino de metodologias qualitativa, colocam os problemas que aplicam-se também a uma relação de orientação. De uma forma geral sempre que se fala do ensino e aplicação de metodologias qualitativas, neste congresso, e nas universidades em geral quando é necessário fazer escolhas em relação a uma Dissertação de Mestrado ou Tese de Douramento o tema e os problemas são amplamente discutidas.

Neste artigo está presente uma abordagem auto-etnográfica (Hughes \& Pennigton, 2017), os autores deste texto defendem que os orientadores e alunos orientados na sua relação partem das suas experiencias pessoais e académicas na forma uma investigação se desenvolve. No caso dos autores deste texto reflectem também as suas experiências académicas e as suas opções seguem a linha metodologia orientada para o contexto e o investigador. Realizou-se uma revisão da literatura, a qual incluiu estas e outras obras, chegando à conclusão que não há livro de metodologia que não fale deste tema directa ou indirectamente, mas espalhado em várias páginas, por exemplo em Rossman e Rallis (2017) parece que o orientador não existe, mas na fase formação, é suposto o acompanhamento institucional e as fases de referência de uma investigação e orientação estão presentes. Outro exemplo Bryman (2016) o orientador surge mencionado uma vez, mas em Silverman (2017) esta figura surge implícita e explicitamente ao longo do texto. Encontrou-se, no entanto autores que se dedicam ao tema, das quais destacam-se, Beaud (2006) apresenta esquematicamente como faz-se uma orientação, e Johnson (2016) mostra os problemas que se colocam aos orientadores nesta área.

A literatura consultada revelou que o tema é complexo, o que levou aos autores deste texto, a escrever dois artigos independentes, mas que se complementam, um mais teórico e filosófico e outro mais prático tendo uma investigação, em comum, ambas utilizam a metodologia orientada para o contexto e o investigador.

O título deste artigo é "Orientar Segundo a Metodologia Orientada para o Contexto e o Investigador", evoca a importância da teoria, teorização e filosofar nas Ciências Sociais. A filosofia permite a sistematização e organização do conhecimento em vários ângulos permitindo a discussão (Husserl, 2009). Observa-se que a filosofia tem sido mal vista, utilizase, em vez disso o termo paradigma (Lincoln \& Guba, 1985), e a teoria é uma forma de fixar 
e dar coerência aos conhecimentos produzidos que (Gadamer, 2001) intimamente ligados ao contexto histórico e social de onde surgiram. A teoria é vista como uma fotografia (Becker, 1998; Blumer,1969) que integra todos os elementos empíricos. Criticamos a tendência (Almeida \& Pinto, 1986) de desvalorizar a teoria e a reflexão sobre as práticas científicas em detrimento da parte empírica, perde-se assim a profundidade, coerência e lógica do conhecimento produzido.

A metodologia orientada para o contexto e para o investigador tem origem na Grounded Theory, onde Glasser e Strauss (1967) propõem-se construir teorias a partir de dados. Na aplicação desta metodologia à orientação, defende-se que o trabalho de um orientador e um investigador não está apenas em construir, testar e melhorar teorias, mas também em tornarse numa ferramenta que permita fundamentar teorias ao inverter o processo de investigação. Um dos desafios que se coloca ao investigador, está em fundamentar as suas opções teóricas, metodológicas e decisões que toma ao longo do processo de investigação. Este tem a necessidade de compreender e integrar teoricamente os seus dados assim como tem de defender o seu trabalho diante de um júri.

O tema da orientação académica está centrado em dois actores, o orientador e o investigador aluno de mestrado ou doutoramento. Há uma proximidade que existe nesta relação que leva a entrarmos na investigação fenomenológica, temos por centro a experiência e a vivência humana, (Moustakas, 1994), em que está presente uma atitude de escuta do outro, de autoconhecimento tão importantes na relação orientador com o orientando e na relação com os participantes (Finlay, 2011).

\section{ORIENTAR UMA CONCEPÇÃO ECOLÓGICA DE INVESTIGAÇÃO}

Orientar trabalhos académicos, especialmente Dissertações de mestrado e Teses de Doutoramento implica ter uma concepção de investigação ecológica. Segundo esta, o orientador e aluno orientado, tomam as suas decisões e situam-se em função de um contexto específico. Nesta relação estão presentes actores, uma localização e relações sociais, dito de outro modo, os eventos e as decisões localizadas em contextos concretos, situados em um tempo histórico que o torna único. Está ainda presente a complexidade com relações entre múltiplos elementos, onde ambos nem são totalmente contingentes nem totalmente independentes (Abbot, 2016). A incerteza, a constante reorganização que surge numa investigação atribui um grau de liberdade que permite a descoberta e o conhecimento. A investigação, neste contexto, é uma experiência holística (Sultan, 2019), onde os participantes 
são colaboradores na investigação. Diverge-se, assim de uma concepção clássica de investigação que separa o investigador do sujeito de estudo, afirmando que este corporiza e experimenta a vida do que se passa no campo. Passando esta filosofia para a relação entre orientador e orientando, ambos são colaboradores na investigação, há uma relação de proximidade, essencial para que estes possam coordenar o trabalho e permitir uma compreensão mútua.

Perante a complexidade e a incerteza, o investigador e o orientador necessitam de um modelo simples, acessível e flexível de investigação. Neste modelo, combinamos um modelo circular, investigação à imagem da Grounded Theory (Corbin \& Strauss, 2015) com um modelo linear de uma visão clássica (Beaud, 2006). O centro da atenção do trabalho académico vem do contexto onde se faz a investigação, e é este que domina todo o trabalho a efectuar. Os elementos de uma investigação mantidos, mas até ao fim desta, são mantidos em aberto, deste modo, permitem ajustar-se ao campo e à descoberta de novos elementos.

A imagem que tem-se do processo de investigação, é baseado em Holstein e Gubrium (2004). A forma como nós autores deste artigo, interpretamos a contribuição destes autores, vemos a investigação como um caminho que visa chegar a um destino ou fim. O investigador vai percorrendo as várias etapas recolhendo informação através de metodologias, métodos e técnicas, observando o que vai acontecendo. Esta recolha de informação é feita parando nos momentos principais e sempre que se justifique. Este não tem tempo para voltar para trás quando lhe falta um detalhe ou comete um erro, mesmo que o faça a situação já mudou e estará a andar sempre em frente. $O$ que pode fazer e analisar em profundidade o que recolheu, melhorar o que está a fazer assim como o que fará a seguir. Procederá assim até chegar ao seu destino, com um relatório final da investigação social. Pode-se dizer isto de outro modo, o que todos os actos e procedimentos associados a uma investigação feitos num momento passado fazem parte do presente, estes condicionam e preparam o que se fará no futuro.

\subsection{Questões Terminológicas: Mentor ou Orientador?}

Usualmente no final da parte escolar de um mestrado ou doutoramento, os alunos necessitam de um orientador para prosseguir para a fase de investigação. O que a literatura diz é que a relação entre o professor que orienta e o aluno que orienta podem ser problemáticas, por exemplo, Eco (1991) tem uma secção com o sugestivo título de como o aluno evitar ser 
explorado pelo orientador. Num olhar mais positivo, que ambas as partes neste processo necessitam de ter consciência das condições necessárias quer para orientar quer para fazer investigação (Silverman, 2017). Neste artigo surgem três figuras centrais, o orientador, o mentor e o que defendemos, o orientador mentor.

Atrás destas três figuras, está um problema que, utilizando o termo de Glasser (1998), minus menthoring, significa que o aluno à saída da parte escolar, deveria ser autónomo para recorrer ao orientador apenas para monitorização, aconselhamento e situações que não saiba resolver por si mesmo. As falhas de formação farão com que este fique demasiadamente dependente do orientador.

A outra crítica vem de Silverman (2017), a formação demasiado teórica dificulta o trabalho do investigador, recomenda que na parte escolar o aluno faça um estudo piloto e neste período, este adquira as competências práticas de que vão necessitar. Um terceiro e último problema refere duas situações: na primeira, o aluno está numa situação relação de dependência e fragilidade em relação ao orientador, seguindo os interesses deste em detrimento daquilo que o trouxe para fazer um mestrado ou doutoramento; na segunda, (Silverman, 2017) a falta de orientação que leva a que o aluno fique sozinho, sendo que consegue fazer o seu trabalho, recorrendo a (Quivy \& Campenhoud, 1992) peritos, professores e colegas que funcionam como mentores. O afirma-se nesta frase com base em Glasser (1998) e (Silverman, 2017) e muitos outros autores é que no final da parte escolar de um mestrado ou doutoramento o aluno deve ter os conhecimentos para ser autónomo e não depender excessivamente do orientador.

Pessoalmente os autores deste artigo, afirmam criticando, que um sistema que promove a excessiva dependência do orientador, estão a prestar um mau serviço ao meio académico e ao aluno. Colocam-se então as questões terminológicas, com a pergunta, o que é um orientador? O orientador é a figura formal que está presente nos momentos principais da investigação. Beaud (2006) mostra como se pode fazer uma boa orientação no modelo clássico, o orientador estabelece um calendário onde estão definidos os principais momentos da investigação, nesses momentos está implícita a autonomia do investigador, mas também o papel de supervisão do mesmo que ajuda o aluno a corrigir e a estruturar o seu trabalho. É uma relação clara, recíproca, hierárquica em que cada um sabe o que tem a fazer, baseado em entendimentos comuns construídos momento a momento. 
O mentor em comparação com o orientador é uma figura informal comparando-o com o formalismo de um orientador. A sua utilidade é evidente, na literatura, Johnson (2016), resume bem a sua utilidade e seu uso no meio académico que adaptamos a nossa metodologia. $O$ mentor é um aluno ou professor com muita experiência que apoiam colegas ou alunos não graduados. No caso deste artigo incide apenas em professores, cuja função é acompanhar os alunos que começam o seu mestrado ou doutoramento e por isso não possuem conhecimento quer da instituição quer da universidade. Este professor estabelece uma relação pessoal, duradoura e recíproca. Podería-se dizer que a criação de laços pessoais de proximidade tem a função de acompanhar o aluno ao longo do seu percurso académico na instituição, ajudando-o nas suas dificuldades e nas falhas de formação. Promove o desenvolvimento, social, cultural, académico e pessoal, moldando mesmo a identidade do aluno que apoia.

$\mathrm{O}$ orientador mentor alia a formalidade do orientador com a informalidade do mentor. $\mathrm{Na}$ orientação há um papel de neutralidade (Johnson, 2016; Silverman, 2017) e uma distância que permite ver os problemas com uma clareza mas por outro lado a mesma distância dificulta uma comunicação eficaz. O mentor é mais informal, mais emotivo, pode ajudar o investigador mais de perto, mas um envolvimento não ajuda a ter uma visão clara dos problemas, podendo mesmo levar a interpretações erradas. De um certo modo Johnson (2016) admite que um mentor pode estar aliado a um orientador e ambos podem complementar-se. Quando um aluno entra num mestrado ou doutoramento após anos de afastamento do meio académico, se for trabalhador estudante, acumule o papel de pai ou mãe de família, for portador de uma deficiência, limitação ou característica específica que implique uma maior atenção, necessitará não apenas de um orientador mas de um mentor e um professor que o ajude em todo processo de investigação.

\section{ORIENTAÇÃO COMO CENTRO DA ATENÇÃO DE UMA INVESTIGAÇÃO}

A orientação como centro da investigação está na relação entre orientador e aluno orientado, incluindo as relações que estes têm com os participantes. Independentemente da dimensão e tipo de investigação, esta abordagem encontra-se a nível micro, tem por objectivo estudar a especificidade de cada contexto e por conseguinte não visa generalizações. O objectivo é construir investigações que se adeqúem ao locais e contextos estudados adaptados quer ao investigador quer aos participantes. 
Estudar a orientação de trabalhos em meio académico implica privilegiar o olhar para dentro, para o docente orientador e para o aluno para as suas características na relação privilegiada entre estes. Para esse efeito juntamos contribuições dos diversos elementos das Ciências Sociais, as quais são: as histórias de vida (Bertaux, 2016), estudam os percursos de vida de uma pessoa no seu contexto histórico, no caso do orientador e orientando; na obra colectiva de Berthelot (2018), onde diversos autores falam da constituição e autonomia das diferentes ciências sociais, centrada na epistemologia das ciências sociais, no nosso caso observamos como constrói uma investigação e esta ganha coerência; na auto-etnografia revela-se que o investigador leva para o campo os seus referenciais culturais e estes são uteis no desenvolvimento da investigação (Chang, 2008), este faz múltiplas sínteses juntando diferentes culturas, experiências (Hughes \& Pennigton, 2017) e tratando-se do trabalho colaborativo entre orientador e orientando é o que (Chang, Ngunjiri, \& Hernandez, 2013) chama-se de auto-etnografia colaborativa; por último na orientação um trabalho colaborativo, mas parte-se da ideia de (Sultan, 2019) que todos os que intervêm directamente na investigação, formam uma equipa.

Neste momento é importante abordar os principais pontos que fazem parte de uma teoria relacionada com a metodologia adaptada ao contexto e ao investigador. As questões levantadas por cada ponto são do foro relacional e fruto das interacções entre os diversos actores, estas são: a questão da objectividade, o eu na orientação, o nós na criação de uma identidade, o outro como ruptura epistemológica e por último o orientador com um papel terapêutico. Sucintamente observemos qual é a contribuição de cada ponto:

- A subjectividade, intersubjectividade e objectividade são termos que se colocam à orientação, adaptamos a contribuição de Schütz (2008) a esta realidade. A subjectividade tem a ver com o eu e as suas vivências. O orientador e orientando partem das suas experiências biográficas, naturalmente subjectivas com uma racionalidade própria. A intersubjectividade são compostas pelos entendimentos e valores comuns base de todo o conhecimento, em que o orientador e o orientando criam entendimentos que possibilitam trabalharem em conjunto. A objectividade, não significa olhar para a realidade do ponto de vista exterior com um olhar de um observador desinteressado, mas sim apropriar-se ou conhecer um objecto interiorizando-o na sua vivência e proximidade.

- O eu na orientação é traduzido com o termo identidade pela dificuldade objectiva de perceber o mesmo objectivamente (Kaufmann, 2010). É um conceito complexo fruto do meio social e histórico com sentimentos de pertença contraditórios, subjectivos e pertença a vários grupos e 
níveis do micro ao macro. Na relação entre orientador e orientando existem ideias preconcebidas do que cada um é, quer e pretende fazer. Rossman e Rallis (2017), neste mesmo sentido, mostram que quando um aluno chega à universidade, este traz consigo as suas experiências, características e uma história que vai guiar as suas escolhas. $\mathrm{O}$ orientador tem que procurar orientar a investigação tendo em conta a especificidade, objectivos e expectativas do investigador, conjugando os interesses da universidade e do campo.

- O nós é composto por uma pequena unidade composta entre o orientador e o orientando, onde estão presentes muitos nós, que medeiam esta unidade. Ambas as partes desta unidade, no contexto do orientador mentor, constituem-se como uma investigação colaborativa. Uma investigação colaborativa (Bourassa, Leclerc, \& Fournier, 2012) surge em volta de um projecto de investigação onde os diversos parceiros estruturam, acompanham e produzem conhecimentos.

- O outro situa-se no campo da ruptura epistemológica. O problema do senso comum está em principalmente por ser se expressar de uma forma imediata, sem passar pela crítica, reflexão e que não é verificável. A familiaridade consiste em explicar o mundo partindo da visão do grupo social do investigador e não do que se quer estudar (Silva, 1986). No campo do orientador mentor, o problema está na demasiada proximidade e envolvimento do orientador em relação ao seu orientando que o impede de ter uma visão clara dos problemas, e dos progressos da própria investigação (Johnson, 2016). Isto significa que a criação de uma identidade comum, de existir envolvimento não elimina o eu e o outro com papéis e funções diferentes num processo de orientação. Pélo contrário exige-se a ambos momentos de reflexividade e afastamento para ter uma visão clara do trabalho que se está a fazer.

- O orientador tem um papel "terapêutico" em relação ao seu orientando por quatro razões: fazer investigação pode prejudicar quer o investigador quer os participantes (Hammersley \& Traianou, 2012) correndo estes riscos físicos e psicológicos, sendo que o afectam pessoalmente o investigador e este necessita de uma atitude terapêutica por parte do orientador; o orientador tem um papel de psicólogo ou terapeuta, há uma atitude de escuta e linha de interrogações cujo objectivo é fazer com que o investigador tome consciência de qual é o seu problema e qual é a solução para o mesmo (Neto \& Baptista, 2019); o orientador não vai para o campo, sendo que a relação com este é mediada pelo orientando, (Bloomberg \& Volpe, 2019) este pode ajudar o investigador que orienta se este tiver consciência do que acontece no campo, como este pensa e se sente nesta situação concreta; na orientação é necessário ter uma visão holística do aluno, onde, (Gardner \& Barnes, 2014; Rossman \& Rallis, 2017), há que juntar as múltiplas dimensões de todas as partes, nomeadamente percurso de vida, recursos, formação, 
características, origens familiares, entre outras que nem sempre são explicitas, mas que vão-se revelando e juntando aos poucos.

Orientar e ser orientado é algo de complexo, podemos observar a multiplicidade de factores que estão envolvidos na especificidade de cada investigação como um todo. Não encontramos a resposta apenas nestes elementos, há que procurar respostas no campo da pedagogia.

\section{PEDAGOGIA ORIENTADA PARA O CONTEXTO E PARA O INVESTIGADOR}

A resposta para a relação entre orientador e investigador está na pedagogia. No nosso entendimento, a relação pedagógica é universal, estejam envolvidos crianças ou adultos. Neste sentido Piaget (1999) indica que as crianças e adolescentes, necessitam de ultrapassar o seu egocentrismo para aprender, e os jovens e adultos num quadro de senso comum (Silva, 1986) necessitam de ir além de si próprios para produzir conhecimento.

Em termos pedagógicos baseámo-nos na fenomenologia presente nas obras de Max Van Manen. A primeira pergunta que fazemos, é o que é a pedagogia? Abstraindo-nos do facto que o autor refere-se a crianças e aplicando o conceito de uma forma mais abstracta, (Van Manen, 2016) a actividade pedagógica significa cuidar, sendo que professores e orientadores têm um papel formativo. No caso da orientação no campo da investigação, o aluno tem lacunas e fragilidades nos seus conhecimentos que têm de ser cobertas com formação. $A$ orientação, tem uma dimensão ética procurando promover quem é orientado e não o prejudicar ou magoar, isso implica ir além do mero campo formal, mas também um olhar sensível e sensitivo para a situação daquele aluno.

Começamos a falar deste tema com o termo de Van Manen (1991) que designa por pedagogical thoughtfulness que corresponde a uma pedagogia ponderada ou cuidada, em termos orientação significa necessidade da proximidade entre orientador e aluno orientado, implica a compreensão utilizado a capacidade de escuta e perceber o que o aluno apresenta, na sua situação concreta, procura fazer os alunos crescer academicamente, profissionalmente, socialmente como seres humanos, tornando-os independentes e autónomos. Na relação pedagógica, de facto, o orientador tem de compreender a situação, no caso do autor, a criança, aqui o professor compreendendo o aluno, toma acções mais ou menos activas mas que tenham significado. 
A relação pedagógica entre orientador e aluno orientado como centro da investigação colocase como problema. O problema apresentado (Van Manen, 2016a,) tem três aspectos: orientadores e orientando estão tão envolvidos com aspectos técnicos que esquecem que o centro são os participantes e como estes vivem o fenómeno social em estudo através das suas experiências; a tendência para a abstracção leva a afastar-se da realidade social dos participantes esquecendo que o conhecimento tem como destino beneficiar os mesmos; na fenomenologia é importante a experiência vivida, a forma de estar no mundo, os modos de vida e ao seu significado. Podia-se concluir que quando o investigador está demasiado preocupado com aspectos teóricos, metodológicos e técnicos, esquece-se de olhar para os dados e os acontecimentos com a devida atenção, para ver o que significa para este e o potencial que estes elementos têm para acrescentar algo ao conhecimento.

A investigação tem associada uma multiplicidade de situações nem sempre claras. Numa relação pedagógica o orientador tem o dever de lembrar isso ao seu aluno e prepara-lo para lidar com a incerteza. Adaptamos o que de Van Manen (2016b) apresenta na obra colectiva em que é organizador, Writing in the dark: phenomenological studies in interpretative inquiry, à orientação. A ideia central é que há uma dificuldade em transformar em palavras, escrever as vivências dos participantes, o que recolhemos no campo de um modo fiel e correcto. Há uma diferença entre o que os dados apresentam, o que o investigador quer escrever e o que as palavras conseguem expressar, resumindo, antes do texto tornar-se claro passa-se por um momento de incerteza e escuridão, que longe de ser negativo, revela aspectos escondidos do trabalho realizado. Na nossa concepção, fazer investigação é um trabalho colaborativo, o orientador deve não só ensinar o aluno a ler o que está nos dados mas ir mais além e qual é o seu significado nas entrelinhas. Isto significa acompanhar de perto o trabalho do aluno em todas as etapas.

O aluno ao trabalhar os seus dados com o seu orientador, não perde autonomia, em caso de dificuldade ganha conhecimento e por seu lado o seu professor fica a saber como este está a trabalhar.

Falar de pedagogia no contexto da orientação, resume-se a uma ideia muito simples, cuidar, estar perto, preparar e acima de tudo acompanhar o aluno, no fundo ser mentor.

\section{CONSTRUTIVISMO COMO UMA CONCEPÇÃO DE INVESTIGAÇÃO}


$\mathrm{Na}$ metodologia adaptada ao contexto e ao investigador qualquer investigação é uma construção social que se constrói sobre o contexto e o investigador (Holstein \& Gubrium, 2004). Na filosofia que se defende aqui, retiram-se os elementos que são precisos de qualquer abordagem que sejam úteis. Aqui estão presentes o positivismo, o construtivismo, a fenomenologia e a Grounded Theory. O mundo social e das Ciências Sociais (Flick, 2007) tanto é externo como é interno ao investigador, o ser humano é fruto do seu ambiente mas simultaneamente modifica o mesmo, não é um agente passivo.

No campo da investigação colocou-se a questão na distinção entre factos e representações sociais, resumindo a ideia que Moscovici (2013) apresenta, é que os factos sociais são representações causais, enquanto as representações sociais baseiam-se em crenças, valores e atitudes partilhadas de um dado grupo. Fazendo uma analogia quando estamos a falar da orientação está em conjugar visões diferentes do campo de investigação, formação e para um mesmo trabalho académico, o que reforça o carácter construído de uma qualquer investigação. Existem muitas formas de ver e pensar um mesmo sujeito de investigação.

O problema colocado à orientação está em dois desafios, construir uma investigação equilibrada e lidar com a incerteza. Na metodologia orientada para o contexto e para o investigador o equilíbrio nasce de existir uma metodologia principal que organiza todas contribuições de outras metodologias (Morse \& Maddox, 2014), no entanto, a principal forma de ter uma investigação equilibrada está em garantir que do início ao fim deste processo o aluno está sempre acompanhado. Quando se fala num processo de investigação realizado por estudantes (Rossman \& Rallis, 2017), o processo começa sempre por este não saber o que quer, o que fazer e como deve fazer, tal é uma construção que se vai consolidando ao longo deste processo. Uma investigação equilibrada significa que tem de ser exequível (Quivy \& Campenhoud, 1992) ou seja passível de ser realizada, temos por modelo, não as grandes investigações mas aquelas que são realizadas por alunos de mestrado e doutoramento, com poucos recursos e tempo limitado. A investigação, neste caso, tem por critério (Robson \& McCartan, 2016, Rossman \& Rallis, 2017) as características do investigador e os seus recursos, o critério da representatividade estatística é substituído pela significância do estudo e sua utilidade, utilizada em pequenos estudos que o aluno consegue fazer.

Lidar com a incerteza é o segundo desafio. Morin (1990) indica que o ser humano procura transformar a incerteza em certeza sem nunca o conseguir. A função da ciência é criar certeza através da criação certeza através do conhecimento mas o seu foco está naquilo que não conhece e na incerteza. Numa perspéctica construtivista (Lock \& Strong, 2010; Silverman, 2017) aprende-se fazendo, por exemplo a escrever praticando a escrita e a certeza quando 
encontram-se nas situações em concreto, através da acção e interacção com todos os elementos que participam na investigação. Do ponto de vista da orientação, orientador e orientando estão sempre a criar. Criam-se quadros onde integram e dão sentido às suas (Goffman, 1991) experiências, ao longo da investigação estão sempre a integrar todos os elementos (Corbin \& Strauss, 2015). O desafio, no entanto, está em fazê-lo de uma forma simples sem perder a sua complexidade, a resposta está nos mapas situacionais, (Clarke, Friese, \& Washburn, 2018) compostos por um quadrado onde se vão colocando os diversos elementos que vão surgindo situando-os, posicionando-os e estabelecendo as relações entre estes. No nosso ponto de vista, os elementos vão surgindo por si, e as relações existem entre si, sem forçar os dados a caber artificialmente e que não correspondem à realidade.

\section{CONCLUSÕES}

Esboçou-se aqui uma teoria da orientação segundo a metodologia orientada para o contexto e o investigador. Como o termo, esboço indica ainda existem limitações a com muitos aspectos para resolver. A primeira é que é um texto principalmente de natureza filosófica e teórica, defende-se a importância de ambas como elementos essenciais do desenvolvimento das Ciências Sociais e Humanas, mas qualquer teoria demora anos a desenvolver, este um dos primeiros artigos que os autores fazem uma abordagem deste tipo para a orientação. $A$ segunda limitação que identificamos tem a ver com um axioma de sempre defendemos, a boa teoria tem de ter uma base empírica (Becker, 1998) e neste momento está-se a fazer a primeira aplicação desta metodologia à orientação. O que existe é uma base filosófica e teórica baseada no ser humano, que é essencial quer para lançar a discussão quer para tornar-se uma ferramenta para aplicar no campo.

O centro da nossa investigação está na relação orientador e orientando, não ignorando as restantes relações externas. O eixo desta filosofia e teoria encontra-se a nível micro, um olhar par o que é único e simultaneamente universal, isto significa que não existem duas relações de orientação iguais mas que é possível identificar dimensões comuns com muitas variáveis variadas e imprevisíveis. Apenas fazer uma investigação como um processo holístico e participativo, participantes, professores, orientador e aluno são colaboradores (Sultan, 2019) permite adaptar a esta ao contexto e ao investigador.

O elemento mais controverso é porém a figura do orientador-mentor, juntando aqui as ideias da pedagogia de (Van Manen, 2016) com as ideias da fenomenologia aplicadas à psicoterapia, (Finlay, 2011). Um orientador é um professor e um psicólogo, fazer investigação 
sempre foi e será um processo exigente com muitas frustrações para o aluno e perigos (Silverman, 2017; Hammersley \& Traianou, 2012), compreender o aluno e a sua situação é o primeiro passo para o sucesso académico. Orientar é procura a complementaridade, estar atento, cuidar e estar mais próximo.

\section{REFERÊNCIAS}

Almeida, J. F., \& Pinto, J. M. (1986). Da Teoria à Investigação Empírica. Problemas Metodológicos Gerais. In Silva, A. S. \& Pinto, J. M. (Orgs.). Metodologia das Ciências Sociais, (pp.30-51). Porto: Porto Editora.

Amado, J. (2013). A formação em investigação qualitativa - problemas, orientações e tópicos In $2^{\circ}$ Congresso Luso-Brasileiro de 16, 17 e 18 de Julho de 2013 Aveiro, Portugal (p. 7). Retrieved from https://ciaiq.org/wpcontent/uploads/2013/11/CLBIQ2013_Programa_Resumos.pdf

Beaud, M. (2006). L'art de la these: comment preparer et rédiger un mémoire de master, une thèse de doctorat ou tout autre travail universitaire à l'ere du net (Nouvele Edition). Paris: Editions la Découverte.

Becker, H. S. (1998). Tricks of the trade: how to think about your research while you're doing it. Chicago: The University of Chicago Press.

Bertaux, D. (2016). Le récit de vie (4⿳a ed). Malakoff: Armand Colin.

Berthelot, J.-M. (2018). Épistemologie des sciences sociales. (2a ed.). Paris: Puf.

Bloomberg, L. D., \& Volpe, M. (2019). Completing your qualitative dissertation: a road map from beginning to end ( $4^{\text {th }}$ ed.). London: SAGE Publications Ltd.

Blumer, H. (1969). Symbolic interactionism. Englewoods Cliffs, N.J.: Prentice-Hall.

Bourassa, B., Leclerc, C., \& Fournier, G. (2012). Assurrer et risquer une posture de recherche collaborative (R.C.). In Boussura, B. \& Boudjaoui, M. (Dirs.), Des recherches collaboratives en sciences humaines et sociales (SHS): enjeux, modalités et limites (pp. 13 - 46). Québec: Les Presses de l'Université Laval.

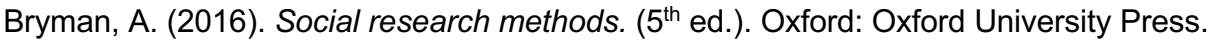

Chang, H. (2008). Autoethnography as method. Walnut Creek: Left Coast Creek.

Chang, H., Ngunjiri, F. W., \& Hernandez, K.-A. C. (2013). Collaborative autoethnography. Walnut Creek: Left Coast Creek.

Clarke, A. E., Friese, C., \& Washburn, R. S. (2018). Grounded Theory after the interpretative turn. (2 ${ }^{\text {nd }}$ ed.). London: SAGE Publications Ltd.

Corbin, J., \& Strauss, A. (2015). Basics of qualitative research: techniques and procedures for developing Grounded Theory. (4 ${ }^{\text {th }}$ Ed.). London: SAGE Publications Ltd.

Eco, U. (1991). Como se faz uma tese em ciências humanas. (5 ed.). Lisboa: Editorial Presença.

Finlay, L. (2011). Phenomenology for therapists: researching the lived world. Main Street, Malden: Wiley-Blakwell.

Flick, U. (2007). Designing qualitative research. London: SAGE Publications Ltd.

Gadamer, H.-G. (2001). Elogio da teoria (J. T. Proença, trad.). Lisboa: Edições 70.

Gardner, S. K., \& Barnes, B. J. (2014). Advising and Mentoring Doctoral Students: A Handbook. (n.p.): Faculty and Staff Monograph Publications.

Glasser, B. J., \& Strauss, A. L. (1967). The discovery of Grounded Theory: strategies for qualitative research. New 
Brunswick: Aldine Transaction.

Goffman, E. (1991). Les cadres de l'expérience. Paris: Les Éditions de Minuit.

Hammersley, M., \& Traianou, A. (2012). Ethics in qualitative research: controversies and context. London: SAGE Publications Ltd.

Holstein, J. A., \& Gubrium, J. F. (2004). Context: working it up, down, and across. In Seale, C., Gobo, G., Gibrium, J. F. \& Silverman, D. (Eds.) Qualitative research practice: concise paperback edition. (pp. 267 - 281). London: SAGE Publications Ltd.

Hughes, S. A., \& Pennigton, J. L. (2017). Autoetnography: process, product, and possibility for critical social research. London: SAGE Publications Ltd.

Husserl, E. (2009). La filosofía ciencia rigorosa (M. García-Baró, trad.). Madrid: Ediciones Encuentro, S.A.

Kaufmann, J.-C. (2010). L'invention de soi: une théorie de l'identité. Paris: Pluriel.

Johnson, W. B. (2016). On being a mentor: a guide for higher education faculty. (2 ${ }^{\text {nd }}$ ed.). New York: Routledge

Lincoln, Y. S., \& Guba, E. G. (1985). Naturalistic Inquiry. London: SAGE Publications Ltd.

Lock, A., \& Strong, T. (2010). Social constructionism: sources and sources and strings in theory and practice. Cambrige University Press.

Morin, E. (1990). Science avec conscience. Paris: Librarie Arthème Fayard.

Robson, C., \& McCartan, K. (2016). Real world research: a resource for users of social research methods in applied settings. ( $4^{\text {th }}$ ed.). London: John Wiley \& Sons Ltd.

Morse, J. M., \& Maddox, L. J. (2014). Analytic Integration in Qualitatively Driven (QUAL) Mixed and Multiple Methods Design. U. Flick (Ed.). The SAGE Handbook of Qualitative Data Analysis (pp. 524 - 553). London: Sage Publications, Ltd.

Moscovici, S. (2013). Le scandale de la pensée sociale: textes inédits sur les représentations sociales réunis et préfacés par Nikos Kalampalis. Paris: Editions de l'École des Hautes Études en Sciences Sociales.

Moustakas, C. (1994). Phenomenological research methods. London: SAGE Publications Ltd.

Neto, D. D., \& Baptista, T. M. (2019). Psicoterapias cognitivo-comportamentais (vol. 1): intervenções clínicas. Lisboa: Edições Silabo.

Piaget, J. (1999). Pedagogia. Lisboa: Instituto Piaget.

Quivy, R., \& Campenhoud, L. V. (1992). Manual de investigação em ciências sociais. Lisboa: Gradiva.

Robson, C., \& McCartan, K. (2016). Real world research: a resource for users of social research methods in applied settings. $\left(4^{\text {th }}\right.$ ed. $)$. London: John Wiley \& Sons Ltd.

Rossman, G. R., \& Rallis, S. F. (2017). An introduction to qualitative research: learning in the field. (4 ${ }^{\text {th }}$ ed.). London: SAGE Publications Ltd.

Schütz, A. (2008). Le chercheur et le quotidien: phénoménologie des sciences sociales. Paris: Klincksieck.

Silverman, D. (2017). Doing Qualitative Research. (5 $5^{\text {th }}$ ed.). London: SAGE Publications Ltd.

Sultan, N. (2019). Heuristic inquiry: researching human experience holistically. London: SAGE Publications Ltd.

Taquette, S. R., Souza, L. M. B., \& Maher, C. F. (2019). Ensino do método de pesquisa qualitativa - proposta pedagógica. In $8^{\circ}$ Congresso Ibero - Americano em investigação Qualitativa, 16 a 19 de Julho. Lisboa: Portugal. Retrived from https://2019.ciaiq.org/wpcontent/uploads/2019/03/Workshop32_CIAIQ2019_EnsinoMetodoPQ_PT_TaquetteSouzaMaher.pdf 
Van Manen, M. (2016). Researching lived experience: human science for an action sensitive pedagogy. London: Routledge.

Van Manen, M. (2016a). Pedagogical tact: knowing what to do when you don't know what to do. London: Routledge.

Van Manen, M. (2016b). Writing in the dark: phenomenological studies in interpretative inquiry. New York: Routledge.

Van Manen, M. (1991). The tact of teaching: the meaning of pedagogical thoughtfulness. Ontario: The Althouse Press. 